Proc. Indian Acad. Sci. (Chem. Sci.), Vol. 107, No. 5, October 1995, p. 601.

(C) Printed in India.

\title{
Errata
}

\section{Resonance Raman intensity analysis of polyatomic molecules}

\author{
N BISWAS, S UMAPATHY, C KALYANARAMAN and \\ N SATHYAMURTHY
}

Vol. 107(3), June 1995, pp 233-244

The following corrections in the article may kindly be taken note of.

$\begin{array}{lcccc}\text { Page no. } & \text { Paragraph } & \text { line no. } & \text { Appeared as } & \text { Should read } \\ 234 & 3 & 3 & \text { time-independent } & \text { time-dependent } \\ 242 & 1 & 8 & \text { (Rau 1990) } & \text { (Rau 1984) } \\ 242 & 2 & 7 & \text { very small well } & \text { very well } \\ 240 & \text { Figure 3(b) } & \text { Caption } & C_{e}-C_{e} \text { torsional mode } & C_{e}-C_{e} \text { stretching mode } \\ 235 & \text { Equation (4) } & \left.|i(t)\rangle=\exp \left(-i H_{e x} t\right) / h\right)|i\rangle & |i(t)\rangle=\exp \left(-i H_{e x} t / \hbar\right)|i\rangle\end{array}$

